INTERNATIONAL JOURNAL OF RESEARCHES IN BIOSCIENCES, AGRICULTURE \& TECHNOLOGY (C) VISHWASHANTI MULTIPURPOSE SOCIETY (Global Peace Multipurpose Society) R. No. MH-659/13(N) www.vmsindia.org

\title{
ONE POT SYNTHESIS OF N- ALKYL AROMATIC AMINES FROM ACETANILIDE UNDER MICROWAVE IRRADIATION IN PRESENCE OF PHASE TRANSFER CATALYST.
}

\author{
Arvind Tapase \\ Department of Chemistry, Abasaheb Marathe Arts and New Commerce, \\ Science College, Rajapur (Vikhare-Gothane) Dist. Ratnagiri 416702 \\ Email: arvindtapase@yahoo.com
}

\section{ABSTRACT}

Number of substituted acetanilide react with alkyl halides, base alcohol and PTC under microwave irradiation to obtain the corresponding $\mathrm{N}$-alkyl acetanilide, which were hydrolyzed by using hydrochloric acid to obtain pure $\mathrm{N}$-alkyl aromatic amines. Microwave assisted organic synthesis has attracted attention due to enhanced reaction rates, higher yields, improved purity, ease of work up after the reaction and ecofriendly reaction conditions compared to the conventional methods.

Keywords: Acetanilide, Alkyl halides, Base, Ethanol, Hydrochloric acid, Aromatic amine.

\section{INTRODUCTION:}

Microwave heating is totally different from conventional heating. In case of conventional heating, the heat gradient is from the heating device to the medium while in case of microwave heating the heat is dissipated inside the irradiated medium (mass heating) and heat transfers from the medium to outside. Again in case of conventional heating, the heat transfer depends on thermal conductivity, on the temperature difference across the material and on convection currents and therefore the temperature increase is often rather slow. While in microwave heating due to the mass heating effect, much faster temperature increase can be obtained depending on microwave power and the loss factor of the material being irradiated. 1

Microwave synthesis represents a major break-through in synthetic methodology. A dramatic change in the way chemical synthesis is performed and in the way it is perceived in the scientific community. Conventional heating, long known to be inefficient and time-consuming, has been recognized to be creatively limiting as well. Microwave synthesis gives organic chemists more time to expand their scientific creativity, test new theories and develop new processes. Instead of spending hours or even days synthesizing a single compound, chemists can now perform that same reaction in minutes. In concert with rapidly expanding applications, microwave synthesis can be effectively applied to any reaction scheme, creating faster reactions, improving yields, and producing cleaner chemistries. 2

Green chemistry involves the design and redesign of chemical synthesis and chemical products to prevent pollution and thereby solve the environmental problems. It incorporates pollution prevention practices in the manufacture of chemicals and promotes industrial ecology. Solution phase reactions performed in the presence of solvent can be either homogeneous or heterogeneous. Homogeneous reactions include standard organic reactions in which all reagents are dissolved in the solvent. Microwave irradiation has been used extensively and successfully with 
homogenous solution phase reactions ${ }^{2}$. Phase transfer catalysis (PTC) is now a commercially mature discipline with over 600 applications covering a wide spectrum of industries such as pharmaceuticals, agrochemicals, perfumes, flavours, dyes, specially polymer and pollution control etc.(3-6) N-alkyl aromatic amines are important intermediates and they find application in almost every important sector of chemical industry such as polymer, pharmaceuticals, dyes and agrochemicals. These compounds are useful in the manufacture of fire resistant plastics $^{7}$ and other polymers made up of urea formaldehyde ${ }^{8}$ or urethane ${ }^{9}$. They were also used as catalyst for the cross linking of polyester(10-11) and as the stabilizer for phenolic resins ${ }^{12}$.

The pharmaceutical applications of $\mathrm{N}$ alkyl aromatic amines include the synthesis of anxiolytics such as diazepam ${ }^{13} \mathrm{~N}$-alkyl 2,6 disubstitued aromatic amines are reported to be useful for the preparation of anti-hypertensive ${ }^{14}$ anti-ulcer ${ }^{15}$ and antiarrythmic agents ${ }^{16} \mathrm{~N}$-alkyl aromatic amines such as N-ethyl aniline are useful as intermediates in the manufacture of disperse dyes ${ }^{17}$. N-monoalkyl anilines are vital intermediates for agrochemicals. These compounds were used as intermediates for the manufacture of herbicides, insecticides and acaricides. They are also useful as intermediates for the preparation of agents controlling ticks and fleas ${ }^{18}$. Some other applications of $\mathrm{N}$-alkyl aromatic amines are in the field of preparation of electrophotographic, photoconductors 19 coagulants $^{20}$ and milling dyes ${ }^{21}$ they were also widely used as antiknock additives for gasoline and diesel fuel ${ }^{22}$. These compounds have been exploited for the extraction and separation of rare earth and noble metals such as uranium and platinum ${ }^{23}$

The present paper reports the remarkable fast synthesis method of N-alkyl aniline via alkylation of acetanilide in presence of solvent under microwave irradiation. The synthesis were carried out by simple mixing base, alcohol and catalyst amount of tetrabutyl ammonium hydrogen sulphate (TBuAHSO 4 ) These mixtures were irradiated in an open beaker in a microwave oven. The results were summarized in Table $\mathbf{1}$

\section{MATERIALS AND METHODS:}

\section{General Procedure for $\mathbf{N}$ - alkylation of acetanilide using phase transfer catalyst.}

acetanilide $(5.0 \mathrm{mmol})$, sodium hydroxide (20 mmol), $5 \mathrm{ml}$ of alcohol and tetrabutyl ammonium hydrogen sulphate $(0.50 \mathrm{mmol})$ as a catalyst were taken in $50 \mathrm{ml}$ beaker, stirred for few second and placed in microwave oven for irradiation at 600 Watt for 40 seconds to obtain acetanilide salt . The mixture was cooled at room temperature. The alkyl halide $(7.5 \mathrm{mmol})$ was mixed with the resulting mixture and was irradiated in microwave oven at 600 Watt for 122 to 145 seconds to obtain $N$ alkyl acetanilide. The reaction was monitored by TLC. After completion of the alkylation reaction, the content was cooled at room temperature. The reaction mixture was extracted with benzene $(20 \mathrm{ml})$ and washed with $(2 \times 25 \mathrm{ml}) 2 \mathrm{~N}$ hydrochloric acid and water to remove unreacted salt. Then it was dried over anhydrous sodium sulphate. On solvent evaporation solid 
products were obtained. The crude product was purified by crystallization using ethanol as a solvent.

\section{EXPERIMENTAL}

All compounds were characterized by modern spectral and elemental techniques. IR spectra was recorded in $\mathrm{KBr}$ disc on a Perkin Elmer spectrometer for all products ${ }^{1} \mathrm{H}$-NMR spectra was recorded on NMR spectrometer in $\mathrm{CDCl}_{3}$ using chloroform as an internal standard. The mass spectra was recorded on GCMS-QP 2010 mass spectrometer. All the reagents used were of AR grade and were used without further purification. The reactions were carried out in microwave oven (CE2977 Samsung).

\section{1a. $\mathbf{N}$-methyl acetanilide}

FT-IR (KBr, Cm-1): $1650 \quad \mathrm{~cm}-1 \quad(\mathrm{C}=\mathrm{C}$ aromatic), $1590 \mathrm{~cm}-1$ (Amide), 3050-3045 (C-H, Aromatic), 2880-2860 cm-1 (C-H Aliphatic)

${ }^{1} \mathrm{H} \mathrm{NMR}\left(\mathrm{CDCl}_{3}\right) 8$ 7.42-7.183(5H, Aromatic), 3.27 (S 3H), 1.87 (S 3H), Mass (ES/MS) M/Z $=197$

\section{1i. 6 Dichloro-N- Methyl acetanilide}

FT-IR $\quad(\mathrm{KBr}, \quad \mathrm{Cm}-1): \quad 1650 \quad \mathrm{~cm}-1 \quad(\mathrm{C}=\mathrm{C}$ aromatic), $1590 \mathrm{~cm}-1$ (Amide), 3050-3045 (C-H, Aromatic), 2880-2860 cm-1 (C-H Aliphatic)

${ }^{1} \mathrm{H}$ NMR $\left(\mathrm{CDCl}_{3}\right) \delta 7.58(2 \mathrm{H}$, Aromatic), $\delta$ $7.62(1 \mathrm{H}$, Aromatic), 3.45 (S 3H), 2.04( $3 \mathrm{H})$, Mass (ES/MS) $M / Z=265$

\section{Hd. $N$-butyl aniline}

FT-IR (KBr, v cm-1): 3364 (N-H), 3059, 3037 (C-H aromatic), 2931, 2871 (C-H aliphatic), 1644 (C=C aromatic). ${ }^{1} \mathrm{H}$ NMR $\left(\mathrm{CDCl}_{3}\right)$ : $7.256-6.566(\mathrm{~m}, 5 \mathrm{H}$,

Aromatic ), 3.910 (t, 2H), 3.526 (s, 1H), $3.073(\mathrm{t}, 2 \mathrm{H}), 1.550(\mathrm{~m}, 2 \mathrm{H}), 1.612(\mathrm{~m}, 2 \mathrm{H})$, $1.398(\mathrm{~m}, 2 \mathrm{H}), 1.377(\mathrm{q}, 2 \mathrm{H}),$,0.939 (t, 3H,), Mass (ES/MS): m/z 149 (M - H).

\section{Hi. 6 Dichloro-N- Methyl aniline}

FT-IR $\quad(\mathrm{KBr}, \quad \mathrm{Cm}-1): \quad 1652 \quad \mathrm{~cm}-1 \quad(\mathrm{C}=\mathrm{C}$ aromatic), 3055-3045 (C-H, Aromatic), 2885-2870 cm-1 (C-H Aliphatic), 3367 (N$\mathrm{H})$,

${ }^{1} \mathrm{H}$ NMR $\left(\mathrm{CDCl}_{3}\right) \delta 7.31(2 \mathrm{H}$, Aromatic), $\delta$ 7.0 $(1 \mathrm{H}$, Aromatic), $4.25(\mathrm{~S} 1 \mathrm{H}), 3.2(\mathrm{~S}, 3 \mathrm{H})$, Mass (ES/MS) $\mathrm{M} / Z=190$

\section{RESULTS AND DISCUSSION:}

Under microwave irradiation, number of substituted acetanilide reacts fast with alkyl halide, base, alcohol and phase transfer catalyst to give corresponding $\mathrm{N}$ alkyl acetanilides, which were hydrolyzed by using hydrochloric acid to obtain pure Nalkyl aromatic amines. The results are summarized in TABLE I and II.

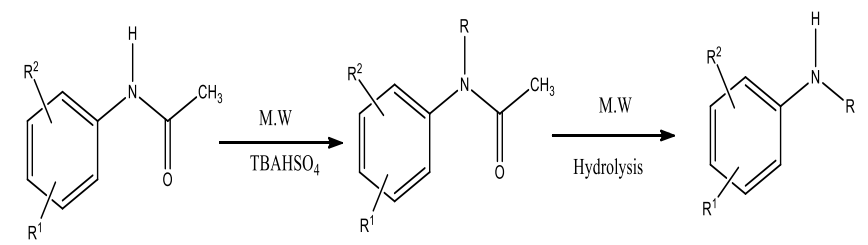

Since the shape and size of the reaction vessel are important factors for the heating of dielectrics in a microwave oven, preferred reaction vessel is a tall beaker of much larger capacity than the volume of the reaction mixture. Superheating of liquids is common under microwave irradiation, thus the strategy of the reactions is to keep the reaction temperature substantially below the boiling point of each compound used for the reaction. Since it is difficult to measure in a household microwave oven, one of the best solution is to repeat an experiment several times increasing slowly power so 
that vapours do not escape outside the beaker after reaction. The work-up procedure is reduced to a treatment with an appropriate solvent (e.g. ethanol) and recrystallization.

The hydrolysis of $\mathrm{N}$-alkyl acetanilide is carried out under microwave irradiation by simple mixing of $\mathrm{N}$-alkyl acetanilide with $10 \% \mathrm{HCl}$ and appropriate time to obtain $\mathrm{N}-$ alkyl aniline. The results are summarized in Table-II

\section{CONCLUSION}

In conclusion, we have developed a simple, efficient and clean methodology for synthesis of $\mathrm{N}$-alkyl aniline that occurs under mild conditions using inexpensive reagents and a microwave oven as the irradiation source. Moreover, this synthesis method of $\mathrm{N}$-alkyl aniline is superior and faster as compared to conventional methods because the starting material used here is acetanilide instead of its sodium salt, which makes the synthesis procedure simple, convenient and safe.

\section{ACKNOWLEDGEMENT}

The author are thankful to the Principal, Abasaheb Marathe Arts and New Commerce, Science College, Rajapur Dist. Ratnagiri for providing necessary facilities.

\section{REFERNCES :}

Desai K. R., Green Chemistry microwave synthesis, first edition, 1, (2005).

Brittany L Hayes, Microwave Synthesis (C) CEM Publishing U.S.A. PP 14, (2002).

Starks C. M., Liotta C. L., Halpern M., Chapman, Hall; Phase Transfer Catalysis, 23 (1994).
Dehmlow E. V., Dehmlow S. S., Phase Transfer Catalysis, 65 (1993).

Sharma M. M, Sasson Y., Neumann R., Hand book of Phase Transfer Catalysis, 168 (1997).

Krishna Kumar V. K., Sharma M. M., Synthesis 558 (1983).

Koenig K. H., Pommer H., Belg. Pat., 606 (1962).

Baruo Har Toshio N., Koyi F., Kazunobu A., Jap. Pat., 72,26,582 (1972).

Murai T., Kon Y., Jap. Pat., 3038 (67), (1967).

Heinz M., Dieter S., Hans S., Hansjoachim T., S. Afr. Pat., 69,04,393 (1970).

Kutepov D. F., Skubin V. K., (USSR) Past. Massy, 18-20 (1972).

Cliernik J., Czech. Pat. 160, 528 (1975).

Iacobescu-ilianu S., Bellu D., Cuiban F., Sci. Pharm. Proc., 25 (1965).

Julius D., George D., H.U.S.P., 3,976,643 (1976).

Julius D., George D., H.U.S.P., 4,183,956 (1980).

McMaster P. D., Byrnes E. W., Feldman H. S., Takman B. H., Tenthorey P. A., J. Med. Chem. 22,1177 (1979).

Straley J. M., Chemistry of Synthetic Dyes, Edtd., By Venkataraman K., 3, 424 (1970).

Willoughby, Ohio, Farm Chemicals Handbook, Pub. By Meister Pub. Co. USA, (1982).

Kalle A. G., B. P., 977, 399 (1964).

Shinohara J., Aoyagl J., Jap. Kokai., 73,97,779 (1973).

Ogawa T., Yatome C., Ishizuka Y., Takase Y., Gifu Diagaku Hokuku, 68-74 (1973). 
Tetsuya I., Showa Oil Co. Ltd. Tokyo Jap. Sekiyu Gakkai Shi,14(7), 512-517 (1971).
Eugeniusz K., Zazislaw B., Witold P., Pol. Pat., 108,076 (1980).

Table - I -Microwave assisted N - alkylation of acetanilide under PTC.

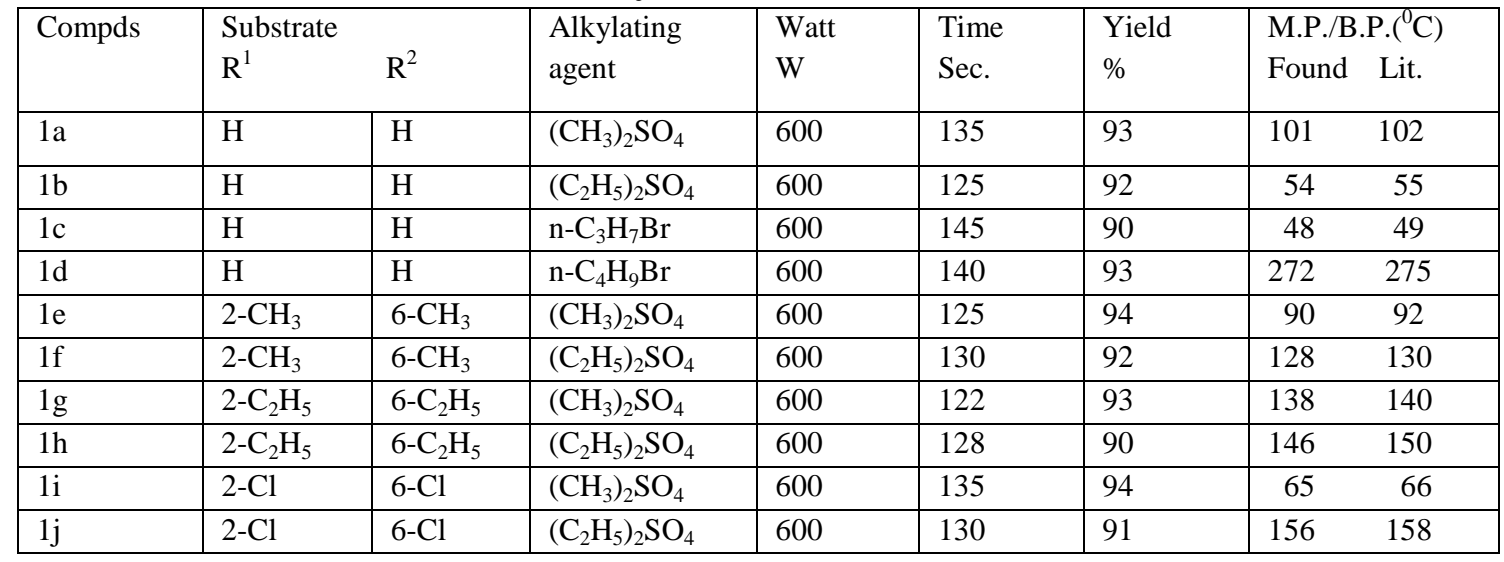

Table - II - Microwave assisted hydrolysis of $\mathbf{N}$ - alkyl acetanilide to $\mathbf{N}$-alkyl aniline

\begin{tabular}{|c|c|c|c|c|c|c|c|}
\hline Compds & $\begin{array}{c}\text { Substrate } \\
\mathrm{R}^{1}\end{array}$ & $\mathrm{R}^{2}$ & & Product & $\begin{array}{r}\text { Yield } \\
\%\end{array}$ & $\begin{array}{l}\text { M.P./ } \\
\text { Founc }\end{array}$ & \\
\hline $\mathrm{Ha}$ & $\mathrm{H}$ & $\mathrm{H}$ & $-\mathrm{CH}_{3}$ & N- Methyl aniline & 90 & 193 & 194 \\
\hline $\mathrm{Hb}$ & $\mathrm{H}$ & $\mathrm{H}$ & $-\mathrm{C}_{2} \mathrm{H}_{5}$ & N- Ethyl aniline & 92 & 202 & 204 \\
\hline $\mathrm{Hc}$ & $\mathrm{H}$ & $\mathrm{H}$ & $\mathrm{n}-\mathrm{C}_{3} \mathrm{H}_{7}$ & N- Propyl aniline & 90 & 220 & 222 \\
\hline $\mathrm{Hd}$ & $\mathrm{H}$ & $\mathrm{H}$ & $\mathrm{n}-\mathrm{C}_{4} \mathrm{H}_{9}$ & $\mathrm{~N}-$ Butyl aniline & 91 & 237 & 240 \\
\hline $\mathrm{He}$ & $2-\mathrm{CH}_{3}$ & $6-\mathrm{CH}_{3}$ & $-\mathrm{CH}_{3}$ & $\mathrm{~N}-2,6$ Trimethyl aniline & 93 & 204 & 206 \\
\hline $\mathrm{Hf}$ & $2-\mathrm{CH}_{3}$ & $6-\mathrm{CH}_{3}$ & $-\mathrm{C}_{2} \mathrm{H}_{5}$ & $\begin{array}{l}\text { N- Ethyl 2,6 dimethyl } \\
\text { aniline }\end{array}$ & 92 & 126 & 128 \\
\hline $\mathrm{Hg}$ & $2-\mathrm{C}_{2} \mathrm{H}_{5}$ & $6-\mathrm{C}_{2} \mathrm{H}_{5}$ & $-\mathrm{CH}_{3}$ & $\begin{array}{l}\text { N- Methyl 2,6 diethyl } \\
\text { aniline }\end{array}$ & 89 & 225 & 229 \\
\hline $\mathrm{Hh}$ & $2-\mathrm{C}_{2} \mathrm{H}_{5}$ & $6-\mathrm{C}_{2} \mathrm{H}_{5}$ & $-\mathrm{C}_{2} \mathrm{H}_{5}$ & N- 2,6 triethyl aniline & 86 & 146 & 148 \\
\hline $\mathrm{Hi}$ & $2-\mathrm{Cl}$ & 6-Cl & $-\mathrm{CH}_{3}$ & $\begin{array}{l}\text { N- Methyl 2,6 dichloro } \\
\text { aniline }\end{array}$ & 93 & 155 & 156 \\
\hline $\mathrm{Hj}$ & $2-\mathrm{Cl}$ & $6-\mathrm{Cl}$ & $-\mathrm{C}_{2} \mathrm{H}_{5}$ & $\begin{array}{l}\text { N- Ethyl 2,6 dichloro } \\
\text { aniline }\end{array}$ & 91 & 168 & 170 \\
\hline
\end{tabular}

